\title{
Research of the coal dust size range influence on low- temperature vortex combustion based on numerical simulation
}

\author{
Ksenia Y. Shcherbakova ${ }^{1 a}$, Pavel S. Gergelizhiu², Boris V. Lebedev ${ }^{3}$ \\ ${ }^{1}$ Engineering Center "Teplouniversal" LLC, 634050 Tomsk, Russia \\ ${ }^{2}$ National Research Tomsk Polytechnic University, 634050 Tomsk, Russia
}

\begin{abstract}
Low-temperature vortex combustion numerical simulation was performed using FIRE-3D software. Low-temperature vortex combustion aerodynamic and heat-andmass transfer versus coal dust size range characteristic were analysed. The results are presented in graphical form. P-49 Nazarovo station steam generator model was created. The results of the numerical modelling are suitable for coal dust size range effect on lowtemperature vortex combustion analysis.
\end{abstract}

\section{Introduction}

It is hard to overrate role of the numerical simulation in modern science. It allows to conduct complicated experiments in relatively short period of time and with much lower cost in comparasing to the same experiments made in real life. For this exact reason present research was based on numerical simulation which allows to evaluate how change of the initial data such as coal dust size range charachteristics influence processes inside a furnace.

Coal dust size range is one of the initial parameters in low-temperature vortex combustion research. It has a great effect on aerodynamic and heat-and-mass transfer due to its key role in stability of the process [1].

The goal of the work presented is to research coal dust size range influence on the combustion processes in low-temperature vortex furnace with Nazarovo deposit brown coal as a primary fuel [2].

\section{Object of study}

Present research is based on low-temperature vortex combustion technology applied on Nazarovo state district power station. №7 one-through $800 \mathrm{t} / \mathrm{hr}$ steam generator of the station was reconstructed for the low-temperature vortex combustion technology. In order to research application of the new technology using the existing steam generator numerical simulation was applied [3]. Model of the steam generator was made using FIRE-3D software [4].

Numerical simulation of P-49 steam generator low-temperature vortex combustion provided data for

a Corresponding author: kseniashcherbakova@gmail.com 
coal dust size range influence analysis on aerodynamics and heat-and-mass transfer inside the furnace. Coarse and fine fractions of the initial fuel: Nazarovo deposit brown coal, were chosen. Table 1 presents initial fuel planting results.

Table 1. Fuel fraction composition

\begin{tabular}{|c|c|c|}
\hline \multirow{2}{*}{$\begin{array}{c}\text { Particle size, } \\
\mu \mathrm{m}\end{array}$} & \multicolumn{2}{|c|}{ Particles content, \% } \\
\cline { 2 - 3 } & Fine fraction & $\begin{array}{c}\text { Coarse } \\
\text { fraction }\end{array}$ \\
\hline 70 & 29 & 26 \\
\hline 150 & 19 & 19 \\
\hline 350 & 30 & 16 \\
\hline 750 & 15 & 20 \\
\hline 1000 & 7 & 19 \\
\hline
\end{tabular}

Simulation was conducted on low-temperature vortex furnace model with excess air ratio $\alpha=1,072$ and fuel rate $\mathrm{Bp}=39,444 \mathrm{~kg} / \mathrm{s}$ and present air regime (table 2).

Table 2. P-49 Air regime

\begin{tabular}{|c|l|c|}
\hline № & \multicolumn{1}{|c|}{ Parameter } & Velocity, $\mathrm{m} / \mathrm{s}$ \\
\hline 1 & Primary airflow from burners & 49 \\
\hline 2 & Secondary airstream from burners & 54 \\
\hline 3 & Eventilate airstream from downdraft & 37 \\
\hline 4 & Main airstream from downdraft & 30 \\
\hline 5 & Airstream from lower tier of tertiary blast & 35 \\
\hline 6 & Airstream from middle tier of tertiary blast & 36 \\
\hline
\end{tabular}

\section{Calculation results}

Figure 1 represents results of the Nazarovo station P-49 steam generator low-temperature vortex combustion numerical simulation. Obtained data analysis shows that a large amount of fine fraction particles is carried up above burners level $(\mathrm{h}=10 \mathrm{~m})$ and into the upper part of the furnace with main flow. Under burners' furnace volume $(\mathrm{H}=0-10 \mathrm{~m})$ is uniformly filled with fuel particles.

Fuel and ash flow with outweighting coarse fraction seen mostly in under burners' furnace volume as it is expected to be for low-temperature vortex combustion. The rest of the flow is carried up above burners' level. Figure 1a-d and 2a-d shows fine and coarse fraction combustion considerably. One can see how fine particles are dragged up and out of the furnace in a greater amount in comparison to coarse fraction fuel particles. Such coal dust flow behavior increases combustible losses if fine fuel fraction is being burned.

Model's aerodynamics shows almost no changes ether fine or coarse fraction is in use (Figure 1a and 2a). There is a uniform upward state-steady $15-20 \mathrm{~m} / \mathrm{s}$ flow along the rear tube wall in mid and upper furnace volume in both cases. Besides, there is $10-15 \mathrm{~m} / \mathrm{s}$ upward flow in under burners' volume. Burner's stream directs the flow to the rear tube wall, where it interacts with lower tier of tertiary blast and goes into the upward flow increasing flow velocity from 5 to $25 \mathrm{~m} / \mathrm{s}$ as a result. Lower tier of tertiary blast doesn't have much influence to aerodynamic structure of observed numerically simulated model's variations. 


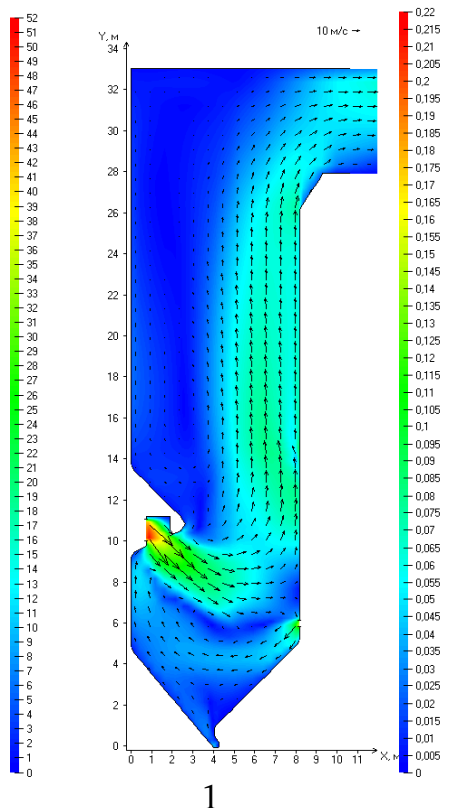

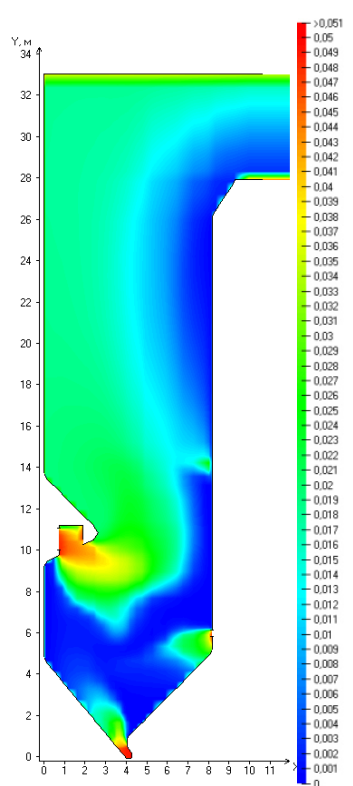

$1 \mathrm{~b}$

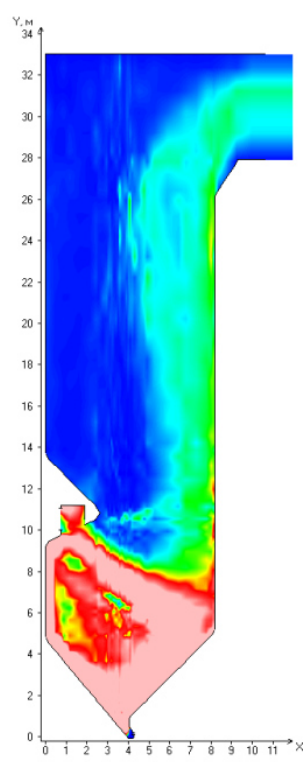

$1 \mathrm{c}$

Figure 1. Fine fraction numerical modeling results: 1a) velocity distribution; 1b) oxygen distribution; 1c) particles distribution.
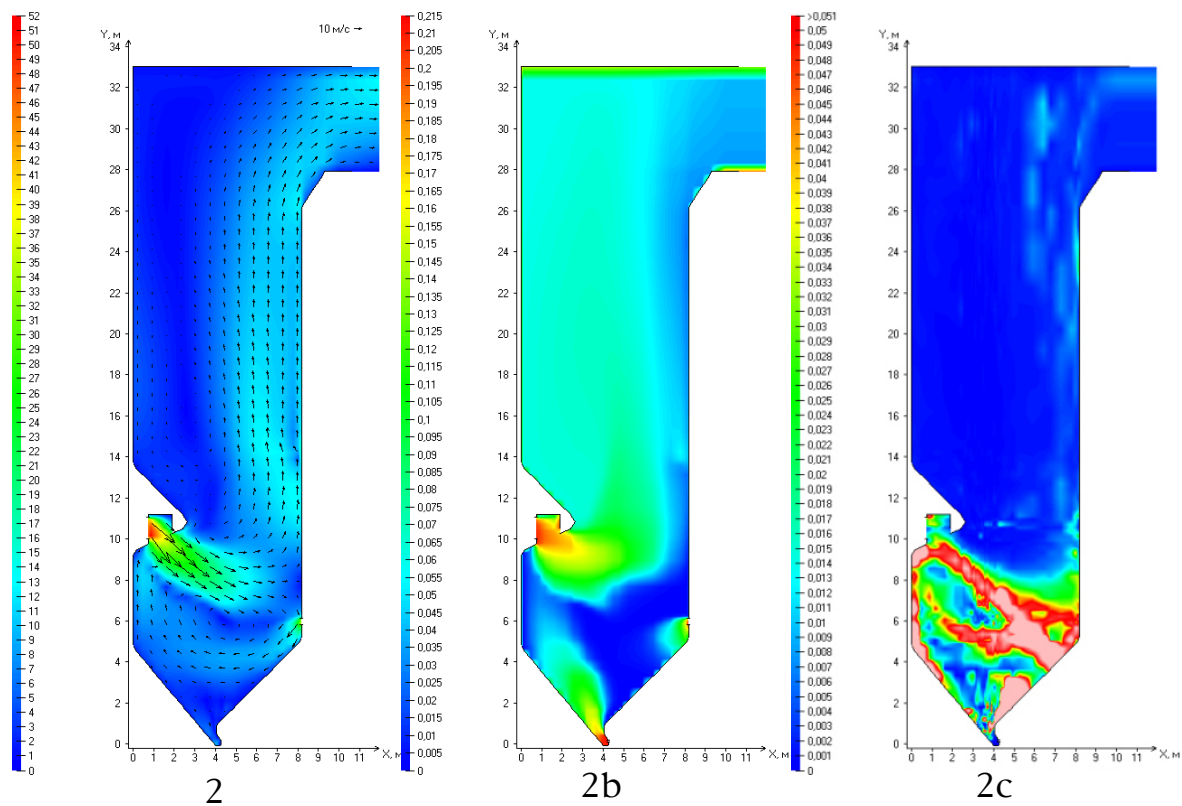

Figure 2. Coarse fraction numerical modeling results: 2a) velocity distribution; 2b) oxygen distribution; 2c) particles distribution.

\section{Conclusion}

Coal dust size range influence analysis on aerodynamics and heat-and-mass transfer of the lowtemperature vortex furnace along with temperature and fuel particle distribution fields in burner cross section has been conducted as the result of the obtained research. 
The numerical simulation of the Nazarovo station P-49 steam generator allows to evaluate how coal dispersion could influence low-temperature vortex furnace combustion. Coarse gridding coal is considered to be more suitable type of fuel. It allows to obtain vortex aerodynamic needed and typical for low-temperature vortex combustion. However, the presented model has been tested using two different coal fractions only: coarse and fine. In order to find optimal for low-temperature vortex combustion coal dust size range characteristic further research of greater variations should be made.

\section{References}

1. B.V. Lebedev, A.S. Zavorin, Mineral matter of a coal distribution in horizontal low-temperature vortex flame, Bulletin of Tomsk Polytechnic University 315, 15-20 (2009) [In Russian]

2. Teplovoy raschet kotlov (Normativny metod). (Saint-Petersburg: SPO CKTI 1998) [In Russian]

3. New modernized power-generating unit was put into service on Nazarovo state district power station. (Newslab.ru, 2013) [In Russian]

4. A.M. Bubenchikov, A.V. Starchenko Numerical modeling of aerodispersive mixings' dymanic and combustion in channels, 221-234 (1998), ISBN 5-7511-1004-8 [In Russian] 